\title{
SCREENING OF BIO ACTIVITY OF DIFFERENT PARTS OF A LEGUMINOUS MEDICINAL PLANT IN VARIOUS SOLVENT EXTRACTS
}

\author{
Punita Tiwari \\ Shivaji Science College, Nagpur, (MS), India. \\ Corresponding author Email : punitatiwari9@yahoo.com
}

\begin{abstract}
:
The present investigation was taken to evaluate the antifungal effect of different parts of $P$. corylifolia prepared in aqueous and in different solvent extracts. The test fungi used were Fusarium oxysporium and Aspergillus fumigatus. The methanol extract(1000 $\mu$ l)of leaf showed maximum inhibition against A.fumigatus $(26 \mathrm{~mm})$ and moderate inhibition against F.oxysporium $(23 \mathrm{~mm})$. Petroleum ether extract $(1000 \mu \mathrm{l})$ of leaf showed maximum inhibition against F.oxysporium $(22 \mathrm{~mm})$ than A.fumigatus $(17 \mathrm{~mm})$.In aqueous extract $50 \%$ aqueous extract of leaf showed higher affectivity i.e. $(20 \mathrm{~mm} \& 19 \mathrm{~mm})$ against F.oxysporium \& A.fumigatus respectively than tender stem extract. It was identified during study that Petroleum ether and methanol extracts of leaf of P. corylifolia is a potent solvent showed highest antifungal activity. The aqueous extract of leaf also showed high antifungal activity at $50 \%$ conc. against test fungal strains.
\end{abstract}

\section{Keywords:}

Psoralea corylifolia, solvent extracts, antifungal activity,Aqueous

\section{Introduction:}

In recent years, several diseases and microbial infections, have shown considerable resistance to a number of antimicrobial agents, such as penicillin, ampicillin, and flouroquinolones among many others(Okeke, et al.,2007)There is an increasing trend in the emergence of resistance to antimicrobial agents, not only due to the poor quality drugs, patient non-compliance, and irrational use of antimicrobial agents, but also to spontaneous mutations within the microbial populations(Ndugulile, et al., 2005). This situation and unknown side effects of certain antibiotics have forced scientists to search for new options as anti microbial substance from various natural sources such as medicinal plants. Medicinal plants represent a rich source of antimicrobial agents (Mahesh and Satish, 2008). Many potent drugs have been purified from 
medicinal plants having antirheumatic, antimalarial, anticancer, antidiabetic and antimicrobial properties (Kaushik et al., 2000). Many recent studies have shown that both crude extracts and purified compounds isolated from plants can be effectively used as natural antifungal agents (Kanwal et al., 2010). Plant based antimicrobials which include antibacterial and antifungal effects represent a vast untapped source of medicines and they provide enormous therapeutic potential. A systemic screening of traditional medicines may result the discovery of novel effective compounds. The need of the hour is to screen a number of medicinal plants for promising biological activity (Chanda et al., 2011). According to WHO reports, about $80 \%$ of world population is taking interest in indigenous medicinal plant remedies (Pirzada et al., 2009).

P.corylifolia linn. Commonly known as babchi, belonging to family leguminosae, distributed widely in a tropical and subtropical region. The plant has been used in indian \& chinese folk, siddha \& Ayurvedic Medicine. P. corilifolia exhibiting antitumour, antibacterial, antimycotic, antioxidant activities used in curing many diseases. Despite the wide range of medicinal use of P. corilifolia, the plant has not received much attention and has not been fully studied. Therefore, the present work has been taken up to investigate the antifungal activity of aqueous and solvent extracts of leaves and tender stem of P.corylifolia L. against some harmful fungi. The systematic study of higher plants for detecting antimicrobial activity is of comparatively recent origin (Indumathy et al., 2011).

\section{Material and Method:}

Plant materials: Leaves and tender stem of Psoralea corylifolia were obtained from the plants grown in the college garden. Seeds were purchased from the local medicinal plant agency in Nagpur city. Leaves, tender stem were washed, air dried and then powdered in mixer grinder and stored in air tight bottles. Preparation of aqueous extracts: 100 grams of thoroughly washed and air dried plant parts of Psoralea corylifolia were macerated with $100 \mathrm{ml}$ of sterile distilled 
water for 5 minutes. The macerate was filtered and centrifuged at $2000 \mathrm{rpm} 50$ minutes. The supernatant was filtered through Whattman filter paper No.1and sterilized at $1200 \mathrm{C}$ for 10 minutes. The extracts were stored in brown bottle aseptically at $5 \mathrm{oC}$ for further use. Preparation of solvent extracts: Solvent extraction was prepared by taking 25 grams of powder in $200 \mathrm{ml}$ of solvent in a conical flask. For best extraction, a soxhlet extractor was used for 48 hours. After this, extracts was concentrated through rotator evaporator which was then stored at 4oC (Chanda, et al., 2011). Test organisms: Two different species of fungi, used during the study were collected from Rajiv Gandhi Institute of Biotechnology, RTM, Nagpur Univ. The test fungi were Fusarium oxysporium and Aspergillus fumigatus. Determination of antifungal activity of Psoralea corylifolia: The antifungal activities of different solvent extracts were determined by Disc diffusion method in Muller Hinton Agar in terms of diameter of zone of inhibition (Bakeht, et al., 2011). The test fungal strains $(200 \mu 1)$ were inoculated onto the media and sterile discs $(7 \mathrm{~mm}$ in diameter) soaked in various concs viz; 10,20,30,40 and 50\% of aqueous extracts and $250 \mu 1,500 \mu 1,750 \mu 1,1000 \mu 1$ concs. of petroleum ether and methanol solvent were introduced onto the media and then plates were incubated for 24 hours at 37oC. Fungal growth was observed by measuring the diameter of zone of inhibition.(Kiran et al., 2011)

\section{Result and Discussion:}

In the present investigation, the maximum inhibition is recorded in terms of zone of inhibition $(\mathrm{mm})$ by disc diffusion method (Bauer et al., 1966). In between the two fungi tested, at different concentration $(10 \%, 20 \%, 30 \%, 40 \%$ and $50 \%$ ) of aqueous extract prepared from leaf and tender stem of $\mathrm{P}$. corylifolia, F. oxysporium recorded the maximum inhibition $(20 \mathrm{~mm})$ in $50 \%$ aqueous extract of Leaf (Fig:3) in comparison to tender stem i.e. 18mm (Fig:1) followed by A.fumigatus (19mm) (Fig:5) with $50 \%$ aqueous extract of leaf \& $17 \mathrm{~mm}$ with $50 \%$ tender stem extract (Table 1,2 ). In the solvent extracts with 
different concentrations of Methanol and Petroleum ether prepared by taking leaf and tender stem as potent testing part of P.corylifolia, Methanol extract of Leaf at $1000 \mu 1$ showed maximum inhibition $(26 \mathrm{~mm})$ against A.fumigatus (Fig: 4) followed by F.oxysporium (23mm) (Fig:2) (Table 3) whereas Petroleum ether showed moderate effect i.e. $17 \mathrm{~mm}$ with A.fumigatus and $22 \mathrm{~mm}$ with F.oxysporium. Methanol extract of tender stem at $1000 \mu 1$ showed maximum inhibition $18 \mathrm{~mm}$ against F.oxysporium and $17 \mathrm{~mm}$ against A.fumigatus as compared to petroleum ether extract i.e. $15 \mathrm{~mm} \& 16 \mathrm{~mm}$ against F.oxysporium $\&$, A.fumigatus respectively (Table 4). The result predicted that methanol and petroleum ether extract of leaf is a potent solvent which showed highest antifungal activity. The aqueous extract of leaf also showed high antifungal activity at 50\% conc. against test fungal strains. Kiran et al., 2011 used aqueous and solvent extracts of seeds of Psoralea corylifolia against five test fungi to evaluate its effect. Hosmani et al., 2012, showed antimicrobial property of leaf parts of P. corylifolia using different solvent extracts. The antimicrobial activity of the leaf extracts, however, is because of its essential oil content (Nakamura et al, 1999; Usha et al, 2010; Hosamani et al, 2011). The present investigation indicate that, P.corylifolia (leaf) is a potent medicinal plant which showed strong bioactivity against harmful and disease causing fungi in both solvent extracts (methanol and petroleum ether) as well as in high conc. of aqueous extract.

\section{Conclusion:}

The present investigation indicate that, P.corylifolia (leaf) is a potent medicinal plant which showed strong bioactivity against harmful and disease causing fungi in both solvent extracts (methanol and petroleum ether) as well as in high conc. of aqueous extract. 


\section{Acknowledgement:}

Author is grateful to D.K. Burghate, Principal and Dr. R.S. Sakundarwar, Head, Department of Botany, Shivaji Science College, Congress Nagar, Nagpur, for facilities provided and Prof. Y.K. Bansal, Department of Biological Sciences, R.D. University, Jabalpur, for guidance.

\section{References:}

Bakeht, J., Ali, H., Khan, M.A., Khan, A., Sayeed, M., Shafi, M., Islam, A. and Tayyab, M. 2011. Antimicrobial activity of different solvents of Linnum with disc diffusion method. Afr. J. Biotec. 10(85):19825-19835. 1. Bauer, A.W., Kirby, W.M.M., Sherris , J.C and Truck, M. 1966. Antibiotic susceptibility testing by a standardized single disk method. Am.J.clin.Pathol 36(3):493-496.

Chanda, S., Kaneria, M. And Nair, R. 2011. Antibacterial activity of P.corylifoilia L. seeds and aerial parts with various extraction methods. Res. J. of Micr. 6(2): 124-131.

Hosamani. P.A, Lakshman, H.C, Sandeepkumar, K. and Hosamani,R. 2011. Antimicrobial activityof leaf extract of Andrographis paniculata Wall. Science research reporter 1(2):92-95.

Hosamani, P.A., Lakshman, H.C., and Sandeepkumar, K. 2012. Antimicrobial activity of leaf extracts of P. corylifolia L. Life Sci. Leaflets. 8: 35-39.

Indumathy, R., Satheesh, K.D., Kolagani, P. and Sashikala, D.G. 2011. Antimicrobial activity of whole plant of Luffa cylindrical against some common pathogenic microorganisms. Inter. J. Pharma. Sci and Drug Res. 3(1):29-341.

Kiran, B., Lalitha, V. And Raveesha, K.A. 2011. Antifungal activity of aqueous and solvent extracts of seeds of P. corylifolia L. against seeds borne Fungi of maize. Inter.J. Phar. Life.Sci. 2(10): 161-164. 
Kaushik, P. and Dhiman,A.K. 2000. Medicinal plants and raw drug of india. Bishen Singh, Mahendra Pal Singh, New Cannaught place, Dehradun.

Kanwal, Q., Hussain, I., Siddique, H.L. and Javaid, A. 2010. Antifungal potential of flavanoids isolated from mango ( Mangifera indica) leaves.Natural products Research. 24: 1131-138.

Mahesh, B. and Satish, S. 2008. Antimicrobial activity of some important medicinal plant against plant and human pathogens. World J. Agri.Sci. 4(5): 839-843.

Nakamura, C.V., Nakamura, U.T., Bando, E., Melo, A.F.N., Cortez, D.A.G. and Filho, B.P.D. 1999.Antibacterial activity of Ocimum gratissimum L. essential oil. Memorias do Instituto Oswaldo Cruz.94 (5): 675-678.

Ndugulile, F., Jureen, R., Harthug, S., Urassa, W. and Langeland, N.2005. Extended Spectrum beta-Lactamases among Gram-negative bacteria of nosocomial origin from an Intensive Care Unit of a tertiary health facility in Tanzania. BMC Infect Dis. 5(86): 2334-39.

Pirzada, A.Z., Shaikh,W., Ghani,K.U. and Laghari,K.A. 2009. Sindh Univ. Res. Jour. (Sci. Ser.).41(2):15-20

Okeke, I.N., Aboderin, O.A., Byarugaba, D.K., Ojo, K.K. and Opintan, J.A.2007. Growing Problem of Multidrug-Resistant Enteric Pathogens in Africa. Emerg Infect Dis. Perspective. 13 (11):393-96.

Usha, R, Sangeetha Sashidharan and Palaniswamy M. 2010. Antimicrobial Activity of a rarely KnownSpecies, Morinda citrifolia L.Ethnobotanical Leaflets 14: 306-11. 
Table no.1: Maximum inhibition in different concentrations of aqueous extracts of Leaf

\begin{tabular}{|l|c|c|c|c|c|}
\hline Fungi & \multicolumn{5}{|c|}{ Maximum Inhibition(mm) } \\
\hline & \multicolumn{4}{|c|}{ Concentration of aqueous extracts of LEAF } \\
\hline & $\mathbf{1 0 \%}$ & $\mathbf{2 0 \%}$ & $\mathbf{3 0 \%}$ & $\mathbf{4 0 \%}$ & $\mathbf{5 0 \%}$ \\
\hline Fusarium oxysporium & $15 \mathrm{~mm}$ & $16 \mathrm{~mm}$ & $18 \mathrm{~mm}$ & $18 \mathrm{~mm}$ & $20 \mathrm{~mm}$ \\
\hline Aspergillus fumigatus & $12 \mathrm{~mm}$ & $15 \mathrm{~mm}$ & $18 \mathrm{~mm}$ & $18 \mathrm{~mm}$ & $19 \mathrm{~mm}$ \\
\hline
\end{tabular}

Table no.2: Maximum inhibition in different concentrations of aqueous extracts of Tender stem.

\begin{tabular}{|c|c|c|c|c|c|}
\hline Fungi & \multicolumn{5}{|c|}{ Maximum Inhibition(mm) } \\
\hline & \multicolumn{4}{|c|}{ Concentration of aqueous extracts of TENDER STEM } \\
\hline & $\mathbf{1 0 \%}$ & $\mathbf{2 0 \%}$ & $\mathbf{3 0 \%}$ & $\mathbf{4 0 \%}$ & $\mathbf{5 0 \%}$ \\
\hline Fusarium oxysporium & $8 \mathrm{~mm}$ & $10 \mathrm{~mm}$ & $12 \mathrm{~mm}$ & $15 \mathrm{~mm}$ & $18 \mathrm{~mm}$ \\
\hline Aspergillus fumigatus & $8 \mathrm{~mm}$ & $11 \mathrm{~mm}$ & $13 \mathrm{~mm}$ & $15 \mathrm{~mm}$ & $17 \mathrm{~mm}$ \\
\hline
\end{tabular}

Table no.3: Maximum inhibition in different concentrations of solvent extracts in Leaf

\begin{tabular}{|c|c|c|c|c|c|c|c|c|}
\hline Fungi & \multicolumn{7}{|c|}{ Maximum Inhibition(mm) } \\
\hline & \multicolumn{7}{|c|}{ Concentration of solvent extracts of LEAF } \\
\hline & \multicolumn{7}{|c|}{ Methanol extract $(\boldsymbol{\mu l})$} & \multicolumn{3}{c|}{ Petroleum ether extract $(\boldsymbol{\mu l})$} \\
\hline & $\mathbf{2 5 0}$ & $\mathbf{5 0 0}$ & $\mathbf{7 5 0}$ & $\mathbf{1 0 0 0}$ & $\mathbf{2 5 0}$ & $\mathbf{5 0 0}$ & $\mathbf{7 5 0}$ & $\mathbf{1 0 0 0}$ \\
\hline $\begin{array}{c}\text { Fusarium } \\
\text { oxysporium }\end{array}$ & $12 \mathrm{~mm}$ & $15 \mathrm{~mm}$ & $18 \mathrm{~mm}$ & $23 \mathrm{~mm}$ & $8 \mathrm{~mm}$ & $11 \mathrm{~mm}$ & $14 \mathrm{~mm}$ & $22 \mathrm{~mm}$ \\
\hline $\begin{array}{c}\text { Aspergillus } \\
\text { fumigatus }\end{array}$ & $10 \mathrm{~mm}$ & $13 \mathrm{~mm}$ & $15 \mathrm{~mm}$ & $26 \mathrm{~mm}$ & $8 \mathrm{~mm}$ & $10 \mathrm{~mm}$ & $15 \mathrm{~mm}$ & $17 \mathrm{~mm}$ \\
\hline
\end{tabular}

Table no.4: Maximum inhibition in different concentrations of solvent extracts in Tender stem.

\begin{tabular}{|c|c|c|c|c|c|c|c|c|}
\hline Fungi & \multicolumn{7}{|c|}{ Maximum Inhibition(mm) } \\
\hline & \multicolumn{7}{|c|}{ Concentration of solvent extracts of Tender stem } \\
\hline & \multicolumn{6}{c|}{ Methanol extract $(\boldsymbol{\mu l})$} & \multicolumn{4}{c|}{ Petroleum extract $(\boldsymbol{\mu l})$} \\
\hline & $\mathbf{2 5 0}$ & $\mathbf{5 0 0}$ & $\mathbf{7 5 0}$ & $\mathbf{1 0 0 0}$ & $\mathbf{2 5 0}$ & $\mathbf{5 0 0}$ & $\mathbf{7 5 0}$ & $\mathbf{1 0 0 0}$ \\
\hline $\begin{array}{c}\text { Fusarium } \\
\text { oxysporium }\end{array}$ & $9 \mathrm{~mm}$ & $11 \mathrm{~mm}$ & $14 \mathrm{~mm}$ & $18 \mathrm{~mm}$ & $8 \mathrm{~mm}$ & $10 \mathrm{~mm}$ & $13 \mathrm{~mm}$ & $15 \mathrm{~mm}$ \\
\hline $\begin{array}{c}\text { Aspergillus } \\
\text { fumigatus }\end{array}$ & $8 \mathrm{~mm}$ & $11 \mathrm{~mm}$ & $13 \mathrm{~mm}$ & $17 \mathrm{~mm}$ & $8 \mathrm{~mm}$ & $10 \mathrm{~mm}$ & $15 \mathrm{~mm}$ & $16 \mathrm{~mm}$ \\
\hline
\end{tabular}




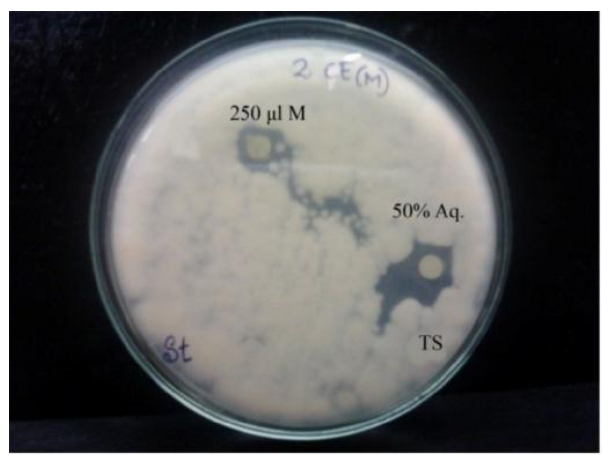

Fig:1Fusarium oxysporium (TS) with $50 \%$ aq. ext

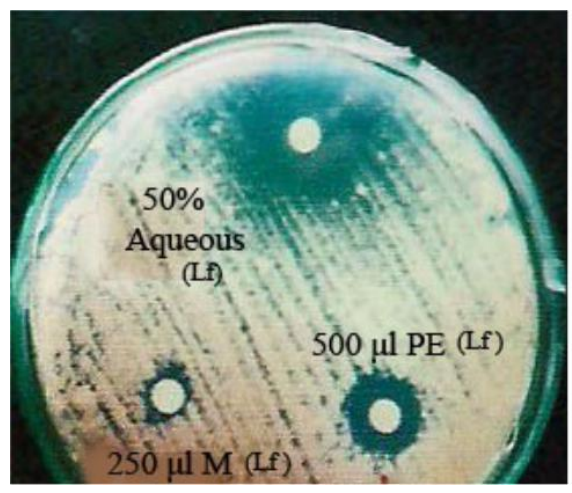

Fig: 3 F. oxysporium $(\mathrm{L})$ : with $50 \%$ aq. ext

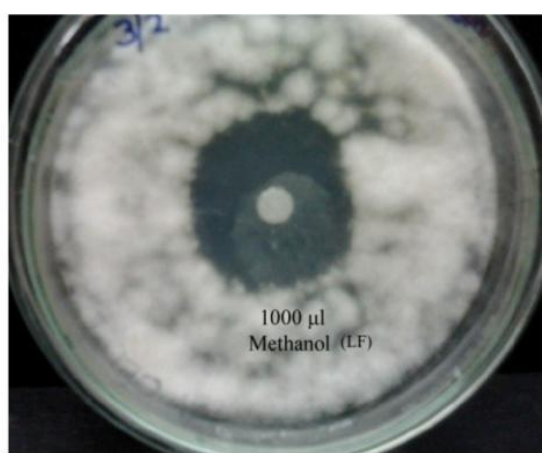

Fig:2 F. oxysporium (L): with $1000 \mu \mathrm{l} M$ ext.

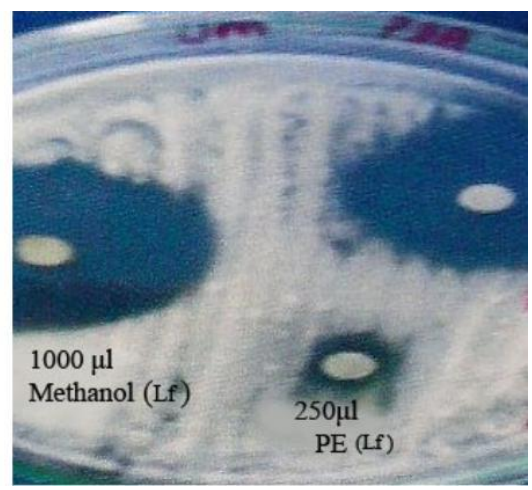

Fig:4 Aspergillus fumigatus (L). $1000 \mu \mathrm{l}$ M.ext and $250 \mu \mathrm{l}$ PE ext

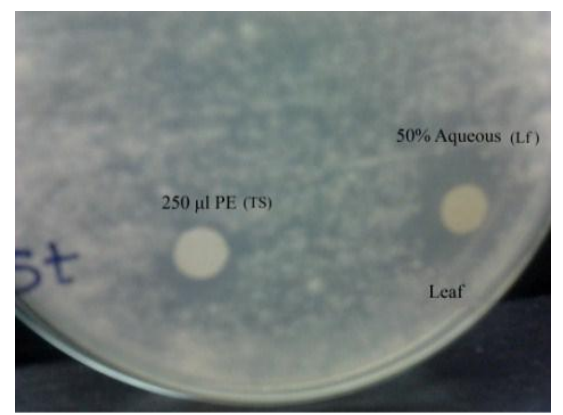

Fig:5 A.fumigatus : with 50\%

aq.ext. (L) and $250 \mu \mathrm{IPE}$ (TS)

(TS- Tender stem, L-Leaf, M-Methanol, PE-Petroleum ether, Aq- Aqueous) 